\title{
Description, diagnosis, prescription: a critique of the application of co-evolutionary models to natural resource management
}

\author{
PAUL JEFFREY* AND BRIAN S. MCINTOSH \\ School of Water Sciences, Cranfield University, College Road, Cranfield, Bedfordshire MK43 0AL, UK
}

Date submitted: 3 March 2006 Date accepted: 31 October 2006

\section{SUMMARY}

To support moves towards more sustainable modes of natural resource management, the research community has been engaged in an evaluation of paradigms, theories and methods which might provide useful and usable insights into such a complex problem set. A particularly influential family of theoretical models concerned with the processes and dynamics of species evolution has been adopted from the fields of biology and ecology. This paper scrutinizes the relevance of biological evolutionary theory to sustainable natural resource management beyond identification of the core analogy, namely that both natural resource management and ecological systems are characterized by multiple interacting elements requiring systemic interpretation. A review of the workings of co-evolutionary theory within its intellectual homeland of biology and ecology leads to a critical evaluation of its use as a descriptive model outside of these domains. Findings from this assessment identify a number of fractures in meaning as the co-evolutionary model is transferred between disciplinary fields, suggesting that the transposition has been conducted without sufficient rigour or consistency. A measured reinterpretation of the applicability of the co-evolutionary model to natural resources management is thereby undertaken. Using water management as a context, the paper posits a series of phenomena which might provide a focus for the application of the co-evolutionary model outside of biology and ecology. In conclusion, the paper argues that the research community needs to move beyond a consideration of the complex implications of coevolutionary processes to the establishment of a firm, process-based definition of co-evolution as a type of change.

Keymords: co-evolution, natural resource management, socio-natural science, sustainability, water management

\footnotetext{
* Correspondence: Dr P. Jeffrey Tel: +44 1234754814 Fax: +44 1234751671 e-mail: p.j.jeffrey@cranfield.ac.uk
}

\section{HANDLING CONNECTION AND COMPLEXITY: A FRAMEWORK FROM THE NATURAL SCIENCES}

The knowledge required to understand how societies adapt to change is dispersed and currently difficult to manipulate in the service of policy formulation. Elements can be found in the literature on economics (industry sector dynamics, innovation processes and risk-taking behaviour), psychology (characteristics of inventors and risk takers), philosophy of science (roles of innovation/invention), sociology (population dynamics, sociology of groups and networks), anthropology (collapse of complex societies) and evolutionary theory (role of diversity and adaptation in survival). In pursuing a comprehensive theoretical framework which allows description of the system and its properties, credible diagnosis of the causes of undesirable system behaviour and legitimate prescription of remedial action or intervention, researchers have been attracted to models sourced from the biological sciences. The reasons for such partiality are not difficult to identify; many of the current threats to sustainable development impact on natural systems and many of the early sustainability paradigms were premised on the preservation and conservation of the natural environment (Thiele 1999).

The starting point for this review is our observation that the investigation of sustainability attracts theoretical frameworks from the natural sciences. Many authors (for example Hodgson 1993; Allen 1994; Funtowicz \& Ravetz 1994; Giampietro 1994; Clark et al. 1995; Funtowicz \& O'Connor 1998) have emphasized that understanding the complexity, variation and uncertainty inherent in living systems is central to the pursuit of sustainability.

Various models of interactive dynamic system relationships have been developed to study human and natural systems with the aim of countering deficiencies in static linear analysis. Many such models have been adopted and adapted from the ecological and biological sciences. These include conceptual frameworks which emphasize processes and phenomena such as complexity, self-organization, adaptation, evolution and coevolution. Perhaps the most intuitively powerful of these is the idea that the development of societies is the compound result of different activities that to some extent fit together and need each other (Norgaard 1994); a process of co-evolution which is typical of many complex systems (Tainter 1988). Indeed, co-evolution is increasingly seen as a useful framework within 
which to consider complex multi-disciplinary issues (Gowdy 1994; Stokes 1994). Authors such as Geldof $(1995 a, b)$ have used such concepts to inform the debate about appropriate natural resource management processes.

The language and semantics of biological theories have been used as a clarion call to recognize the connectedness and mutual dependence of social and natural systems, but we argue that this has been undertaken with little consideration of the limits or utility of the analogies being drawn. Such reservations echo the advice of Samuel Taylor Coleridge (1831) who urged that 'whether you are reflecting for yourself or reasoning with another, make it a rule to ask yourself the precise meaning of the word on which the point in question appears to turn; and if it may be ... used in several senses, then ask which of these the word is at present intended to convey'.

Although the motivations for adapting theory from the natural to the socio-natural sciences are laudable, the way in which these analogies have been constructed and subsequently interpreted are a concern; especially with regard to the use of models of co-evolution. The roots of this concern are twofold. Firstly, models, analogies and theories are at root metaphors, and can thus only ever be partial truths. Without an explicit consideration of the limits of models in both their original (ecology/biology) and proposed (natural resources management) settings, there is no basis on which to advise practitioners on the applicability or reliability of insights or prescriptive advice which emerge from the models' use. Secondly, by adopting and promoting models from one particular field of science, there is a risk that contributions from other intellectual traditions will be discounted or at least disregarded. Not all models are equally useful; there is a need to debate and evaluate the utility of different models as devices to inform the quest for sustainability. The premise that 'we cannot ... guarantee the persistence of any particular system in perpetuity' leads to a view of sustainability as a 'normative ethical principle' which has 'no single version' and is 'a process, not a state' (Robinson et al. 1990). Debating the appropriateness and utility of different models is part of this process, but will not in itself inform management action.

Natural resources management is selected here as the substantive domain within which these debates will be pursued. In particular, we use the challenges posed by water management as a context for evaluating the usefulness of the co-evolutionary model. Water is a resource which has significant impacts on the composition of living systems and the physical environment across a range of scales from individual organisms to whole ecosystems, from a few hours to many hundreds of years. It is a resource that, for the purposes of sustainable management, requires coordinated (or integrated) consideration of a broad range of knowledge from disciplines such as technology, hydrology, ecology, psychology, anthropology and economics to name but a few.

The aims of this paper are twofold. An analytical component involves the exploration and critical assessment of the application of co-evolutionary theories and models to the domain of natural resources management in general and water resource management in particular. This is a task that cannot be robustly undertaken without (1) developing an understanding of the workings of evolutionary and coevolutionary theory, and (2) considering water management as part of a wider set of issues concerned with sustainability and socio-natural interactions. The first task is to clarify the meaning of the models and theories 'on which the point in question appears to turn'. This is the guiding principle behind the following discussions of both evolutionary and coevolutionary theories. Subsequent sections critically review and evaluate how co-evolutionary theory has been transferred and applied to support understanding of socio-natural interactions, the aim being to determine if and how coevolution can be used as a conceptual model for promoting sustainable modes of water management. The second aim of the text is to respond to the critique presented in the opening sections and offer a research agenda which might advance understanding of co-evolutionary processes in the context of water management. We make no claim for the co-evolutionary model to have particular descriptive or prescriptive potency compared with competing perspectives; we simply wish to argue its limitations, counsel against its unconditional application and propose a means for improving its relevance.

\section{DYNAMICS AND EVOLUTION: SYSTEMS AND THEORIES}

A system can be defined generally as being composed of elements, organized in some way and interacting according to some set of rules (von Bertalanffy 1968). For the purposes of this text, systems (as a type of model) are viewed as epistemological devices, languages for conceptualizing the socio-natural world to inform processes of dialogue and action concerned with human use and management of natural resources. As interactions unfold over time, a system will change state; the rules of interaction will map one system state onto another. Such systems exhibit dynamics but, as currently defined, are not evolutionary. The number of types of elements and the form of the rules governing interaction are static.

For a system to be termed 'evolutionary', it must have the potential to change not only state but also $(a)$ structure (in the sense of the range of different types of elements), and (b) the form of its rules of interaction (Klüver 2002). Dynamic processes are those which change state. Evolutionary processes are those which change structure and interaction rules, typically precluding the possibility of previous system states re-occurring. Evolutionary systems are thereby irreversible and are often labelled 'historical' as their current structure, state and rules can only be understood with respect to their unique developmental trajectory. Human systems are evolutionary; they are the product of a dynamic history that has resulted in new instances and types of elements, new configurations of elements and the continued reshaping of relationships between those elements. 
A useful précis of the central characteristics of the evolutionary model is available by paraphrasing Nelson (1995), who describes 'evolutionary' as a class of theories in which: the aim is to understand the change of a variable or a system over time and to explain why it is as it is at a given moment in time in terms of how it got there; and the explanation includes $(a)$ random elements capable of generating or renewing variation in the system in question (the creation of novelty in or renewal of the system state possibility space), (b) mechanisms that winnow on extant variation (selection, the reduction of the system state possibility space), and $(c)$ mechanisms that provide continuity for those elements of the system that survive winnowing (persistence, the maintenance of the system state possibility space).

Do all examples conforming to the definition of evolution given by Klüver (2002) also conform that given by Nelson (1995)? The answer is not obvious as the two definitions focus on different aspects of system change, namely structure and rules (Klüver) versus change in variation (Nelson). Although there is no opportunity to explore a reconciliation of these definitions, it should be noted that further research is needed.

Evolutionary theories are best suited to explain the observed history of systems given that the operation of random elements and novelty limits the ability to predict. Depending on how various types of mechanism (variation generation versus variation winnowing versus variation continuity) are specified, evolutionary theories can be given more or less deterministic (predictable) interpretations. However, in the context of sociocultural evolution, Klüver (2002) concluded that societal change, particularly in modern societies, was unpredictable owing to the inherent dynamics in structure and rules of interaction, something quite different from systems studied by predictive disciplines like physics, where the rules of interaction between system elements are time invariant.

In Neo-Darwinian biological theory (presented as the 'Modern Synthesis' by Julian Huxley 1942) the evolutionary system is the genetic structure of the population (or species). It is here that adaptation occurs through various mechanisms including the natural selection of individual organisms via interaction of their genotype (genetic code) and phenotype (physical expression of the genotype) with their environment. Environmental factors are considered exogenous to, and unaffected by, the organisms as are other populations (except under biological co-evolution, as discussed below). In addition, in biological theory the evolutionary system comprises a population of individual elements of a particular type (i.e. organisms). Although this bounds the system of interest in a particular way, it is important to note that such a bounding decision may not hold special status or validity over other ways of bounding when applying the model to other domains.

Bounding the system of interest shapes how the processes and outcomes of evolution are treated. Ecosystems are not the objects of study in biological evolution and there is a legitimate debate to be had therefore regarding whether it is possible and/or useful to treat the 'evolution' of more than one population of things as a single system, or whether insight can only be gained from treating the populations individually and in relation to each other as separate evolutionary systems. Winder et al. (2005) argue that a focus on populations is fundamental to any evolutionary theory.

But what of those mechanisms which actually drive evolutionary change? In describing and discussing their characteristics it should be remembered that evolutionary models of socio-natural change need not be identical to those developed to explain biological change; as long as they contain the basic elements detailed by Nelson (1995), the mechanisms may differ radically. For example, the mechanism for continuity of biological system variation is genetic reproduction through which traits and structures are inherited by offspring organisms. In biological evolution there is no room for direct inheritance of acquired traits such as the ability to read (socalled Lamarckian inheritance). The creation of novel and extant system variation occurs through genetic recombination and mutation when organisms reproduce, and also through gene flow between populations. The primary mechanism for winnowing on system variation is natural selection operating at the level of the individual organism, but the movement of individuals through space to form new populations can also change variation (for example the founder effect; Futuyma 1986). Further winnowing mechanisms have been proposed for biological evolution including group selection (Mitman 1988; Gould 2002) and self-organization (Kauffman 1993), but these are not widely accepted as part of current NeoDarwinian theory. If the co-evolutionary model is to be applicable to the management of natural resources, then all three of these mechanisms (continuity, variation creation and winnowing/selection) must have corollaries in socionatural systems. However, they need not employ the same mechanisms as those used in biological evolution, or indeed each other. For example, the human ability to write and pass on acquired knowledge from one generation to the next indicates a role for some form of Lamarckian continuity and some authors have incorporated Lamarckian inheritance through learning within human systems (Nelson \& Winter 1982).

\section{CO-EVOLUTIONARY MODELS: FOUNDATIONS IN THE BIOLOGICAL SCIENCES}

Having provided a general description of the properties of evolutionary systems, the debate can move on to consider the nature of co-evolution and co-evolutionary systems. The term co-evolution was coined by Ehrlich and Raven (1964) in their studies of insect pollinator and flower morphology, and can be defined as 'reciprocal natural selection between two or more groups of organisms with close ecological relationships but without exchange of genetic information between the groups' (Odum 1993). It is a process of reciprocal evolutionary change where the dominant traits of one species select those of the other and vice versa through the interaction of phenotypes either directly (such as with insect pollinators and flowers) or indirectly through some medium like a resource (for example beak and food particle size in finches). 
It is the co-evolution of 'linked lives' that has produced Darwin's 'tangled bank' of species, the multitude of forms and interactions that are observed in species. Attempts to understand how the various physical and circumstantial driving forces of Darwin's tangled bank interact have provided some of the most insightful writing on evolutionary theory (for example Thompson 1994; Coyne \& Orr 2004).

For biological/ecological systems, evolution and coevolution involve the same types of changes, dynamics and processes. Co-evolution is a special (but perhaps very pervasive) case of evolution where the focus is on reciprocal influence between evolving systems (populations). So can the processes which underlie co-evolution be characterized and can this characterization help us formulate water policy?

The processes of co-evolution are ultimately the same as those underlying ecological interactions like population and community dynamics combined with those underlying evolutionary change. The following features of the units of change and their environment are central to an understanding of co-evolutionary processes (Thompson 1994).

- The fact that interacting species do not usually occupy exactly the same geographic ranges and that ranges may change over time offers scope for the spread or inhibition of adaptations (new interactions and morphologies) over space and time.

- Environmental conditions at different locations may influence the outcome of interactions making what could be a successful interaction in one location unsuccessful in another.

- Non-perfect mixing of populations over space and time means that the aggregate outcome of many individual to individual interactions (either within or between species) is dependent upon the way in which populations are distributed spatially over time, local environmental conditions and the role of chance.

- Interactions that reciprocally affect fitness need not be continuous in time, nor need they occur in an exclusive 'one-to-one' interaction. It is the mutual effect on fitness that is crucial. Interactions may be many but not all matter equally, and the extent to which particular interactions matter may vary over time.

- In non-continuous asymmetric (i.e. not one-to-one) interactions there may be conflicting pressures from other interactions. Under such conditions there is a recognized problem in defining what constitutes reciprocal change.

However, it is time to draw breath and acknowledge that the deeper we delve into the minutiae of the theory, the less likely we are to be able to clarify its relevance for sustainable natural resources management. Thus, what are the outcomes of a co-evolutionary process and how can they be identified?

Writing in the mid-20th century, authors such as Huxley (1942) and Rensch (1959) thought co-evolution would only produce 'evolutionary dead-end' species too highly specialized to be able to tolerate much change (Thompson 1994). Contributions from, amongst others, Simpson (1965) have changed this view and specialism (or dependency) in interaction between species is now thought:

- to evolve either slowly over time (ancient associations have been observed) or very rapidly (for example introduced insects have been observed as evolving with the spread of monocultured crops to highly specialized feeding forms within a few hundred years);

- not necessarily to lead to extinction as specialist interactions may provide new ways in which species may (co)evolve;

- to potentially be a more advantageous state than generalism depending on environmental conditions and how they change; and

- to potentially provide increased chances of survival and reproduction but possibly also make specialist species 'brittle' or incapable of adapting to environmental changes.

After the extreme specialist view of co-evolution was abandoned, it was thought that co-evolutionary relationships were either 'specific' ('one to one') or 'diffuse' ('one to many', or 'many to many') and that 'diffuse' types were too tangled and complex to be understood. Indeed, co-evolution is thought by some biologists to occur only rarely and only under relatively strong pair-wise interaction (Futuyma 1986). Biologists like Thompson (1994, 2001) and Fox et al. (2001) now advocate a population-centred and explicitly geographic view half-way between evolutionary biology and ecology that seeks to dismantle the 'many to many' or 'one to many' relationships into testable hypotheses linking population and species structure and behaviour explicitly with time and space.

The outcome of interactions under co-evolution is now viewed in terms of possibilities rather than the progressive determinism that used to be prevalent (such as the Spencerian view that the direction of the progression in species is caused by evolution). Much (all?) depends on the way in which populations mix and interact over space and time, the way in which environmental conditions change at a local level and the way in which these conditions influence the outcome of interactions both within and between species.

In a co-evolutionary process, systems change in response to partly stochastic changes in each other with the consequence that their direction of change is not fixed and not predictable (Norgaard 1994). Indeed, in biological theory, co-evolution has been noted as being capable of producing either system stability or instability (Futuyma 1986). However, there is no a priori way of determining whether stability or instability will occur; such determinism is precluded by the role of stochasticity, local differences in individual interactions and how these generate aggregate outcomes.

So co-evolution is a set of reciprocal evolutionary processes that may operate tightly (one-to-one) or more diffusely (manyto-many), may change the distribution of individual characters within coevolving populations potentially leading to the emergence of novelty, may favour specialism or generalism in interactions depending on context, may promote instability or stability for the interacting populations, may operate relatively rapidly or relatively slowly, and may exert a temporary or 
permanent, local or global (i.e. species-level) effect in terms of adaptation. Should the co-evolutionary model be adopted as an adequate description, as a diagnostic tool, or as a basis for prescription? If so, then are practitioners prepared to expose human communities to such a diversity of possible fates? The evidence reported above suggests that even if co-evolutionary traits can be identified and managed, the outcomes of intervention are highly uncertain.

\section{APPLYING CO-EVOLUTIONARY MODELS TO SOCIO-NATURAL PROCESSES}

So what insights can be gained from an appreciation of biological co-evolution in the context of managing interactions between humans and their natural environment? Many fields of scientific enquiry have found the contributions of evolutionary and co-evolutionary theory attractive (see Fiorilo 2001 on economics, Kuznar 2001 on anthropology, Briscoe 1998 on linguistics, Dijksterhuis et al. 1999 on organizational science and McWhorter 2003 on history of language). Most usefully in terms of a contribution to science, co-evolutionary theories provide a model for understanding the relationships between disparate system types. For example Richerson et al. (2002) suggest that the human genetic makeup might have co-evolved with cultural institutions over long time periods, resulting in an innate psychology well adapted to living in cooperative societies. However, attempts to use coevolutionary type models to understand socio-natural systems have been the subject of much recent debate (McIntosh \& Jeffrey 2004; Rammel \& Staudinger 2004). This paper seeks to take that debate forward by challenging the assumption that the co-evolutionary model, as applied to socio-natural systems, is fit for purpose.

The milieu of application for this contribution is socionatural interactions and, in particular, natural resource management. Consequently, the following text critically reviews a selection of recent literature concerned specifically with co-evolutionary understandings of socio-natural relationships, the intention being to demonstrate the extent and influence of such understandings. A more comprehensive review can be found in Kallis (2007).

Aguilera-Klink et al. (2000) and Funtowicz et al. (1998) have used institutional analysis to illustrate the concept of coevolution using, respectively, groundwater management in Tenerife and the economic development of a town in Sicily as case studies. More directly, Van Den Bergh and Stagl (2003) have formulated a framework for institutional analysis itself, based upon the insights of co-evolution. Van Den Bergh and Gowdy (2000), Rammel and Staudinger (2002) and Rammel and Van Den Bergh (2003) have elaborated the policy and economic implications for sustainable development that arise from co-evolutionary theory, focusing on aspects such as path dependency, lock-in and the maintenance of diversity as a strategy to combat uncertainty.

Perhaps the most influential writing on this theme however, has come from Norgaard (Costanza et al. 2004) who importantly suggests an alternative co-evolutionary paradigm for interpreting, understanding and managing the world, including humans (Norgaard 1981, 1984, 1994, 1995). Norgaard views the Earth as a single co-evolutionary system composed of a multitude of co-evolving sub-systems including the environment, human values and human knowledge. He draws a direct analogy between the co-evolution of species with each other and the co-evolution of societies with ecosystems and the physical (resource providing) environment. Everything is endogenous to this vision of socio-natural co-evolution including the abstract human realm of thought.

The importance of cumulative positive-feedback processes is emphasized frequently by Norgaard but no clear distinction is drawn between the functioning of these and of evolutionary processes such as selection (Tisdell 1998). Undoubtedly interdependent dynamic system processes occur between social and environmental domains and are important, but perhaps a more fruitful focus for research concerning the co-evolutionary paradigm lies in:

- improving the clarity of a classification of different kinds of change (dynamic, evolutionary, co-evolutionary);

- characterizing examples of each kind of change to understand the implications for the management and use of water (and more generally other natural resources); and

- developing a clear statement of the nature and extent (limits, differences) of the mapping between biological theory and socio-natural change.

If there is a universally applicable type of change that can be called co-evolution, it should have a definable set of characteristics. The definition provided by Nelson (1995) provides a minimum set of criteria and a language for expressing evolutionary or co-evolutionary phenomena, however there is a gap between Nelson's definition and an operationally useful framework for studying socio-natural processes as a co-evolutionary system.

It is not always easy to understand what is meant by the term 'evolution' outside of biology, and the meaning is often conflated with dynamics in these areas (Klüver 2002). We believe that this is the current case within socio-natural research. There is no consistent framework for researching co-evolution, although there does appear to be an emerging consensus over the implications of characterizing a system as co-evolutionary for policy and sustainability. Typical implications discussed within the literature include risk, uncertainty, path dependency, lock-in, the need to promote adaptivity and problems with policies based on optimization and equilibrium assumptions. Carts and horses come to mind, as a consensus on outputs from the co-evolutionary model (i.e. what it generates as plausible research issues) is emerging before a consensus on model verification and potential benefit has been demonstrated.

So why should a co-evolutionary perspective be privileged over other perspectives? In particular what differentiates coevolution from complex systems? The importance of appreciating complexity is already well-established. What additional 
benefit does co-evolution bring to bear on understandings and management of human-environment interactions? At present the answer is unclear. There is a lack of satisfactory and consistent application of the co-evolutionary framework to real-life cases and problems, despite more than 20 years having transpired since Norgaard's (1981) original work.

\section{APPLYING THE CO-EVOLUTIONARY MODEL TO SOCIO-NATURAL SYSTEMS: FRACTURES IN THE ANALOGY}

There are some specific shortcomings of transferring the coevolutionary model across disciplines and fields of application, although these do not relate to the application of evolutionary or co-evolutionary theory within their homelands of biology and ecology. The frailties described below are associated with attempts to formally transfer the models to other fields of enquiry. Failure to address such points of departure could, by default, allow undue authority and credence to be associated with use of the model outside the remit of biological systems.

The translation of the co-evolutionary model to nonbiological contexts raises a number of points of debate, several of which have been rehearsed in the foregoing pages. Our principal concerns can be summarized under the following five headings.

\section{(1) Specification of suitable populations between} which co-evolutionary relationships might operate

Where are the multiple instances of a species which can be selected on and winnowed? Is it meaningful to talk about a population of rivers, of land uses or of households? Which populations exhibit co-evolutionary change, and which exhibit state-based dynamic change only? Can a population of rivers 'evolve' and if so in what sense? Or is there an alternative way of framing co-evolution? How should co-evolution be bounded and characterized?

\section{(2) Identification of salient or influential co-evolutionary attributes amongst the set of all attributes which an entity might possess}

Co-evolution typically explains the impact of just one attribute of an entity. This might be an important attribute and a key determinant of survival potential. However, given the debate in the biological sciences about the significance and identification of co-evolutionary relationships, it may be relevant to also question whether co-evolutionary processes are only of interest where an intense relationship which might result in 'lock in' or specialization can be identified.

\section{(3) The possibility that the attributes of significance might be intangible}

Whilst natural systems have tangible attribute states, other types of system might have intangible or elusive states, perhaps only expressed as the aggregate outcome over time of the perceptions, intentions and actions of the actors involved. Other forms of interaction may also be occurring in addition to those which might be classified as co-evolutionary; can co-evolutionary interactions be identified through the noise created by the others? Importantly, can state-based dynamic change be distinguished from evolutionary change?

\section{(4) Lack of evidence that evolutionary and} co-evolutionary processes can be harnessed for the benefit of one particular group

Evolutionary processes have no utility function guiding them. The only beneficiary appears to be life itself with individuals and sometimes species being lost simply because they are poorly suited to existing circumstances; does society really want this form of dynamic to inform its approach to socionatural interactions? (This interpretation has recently been pointed out in the context of the global high-tech economy as an emerging ecology with no morals and no objective function; Reich 2001.)

(5) The status of evolutionary theory as having descriptive power but little predictive or prescriptive potential

In adopting the co-evolutionary model the research community may be encumbered by its epistemological standing in that it may simply help to explain what has happened and allow us to characterize and classify processes, to understand what has happened after the fact.

\section{PROGRESSING THE CO-EVOLUTIONARY MODEL}

The challenge is to take some practical steps towards determining whether a single, generalized definition of coevolutionary change can be distilled and applied to the study and management of socio-natural interactions. If we, as a research community, cannot provide and agree upon a single definition (however abstract) of what constitutes co-evolution (as opposed to other types of change) regardless of application area, then we are not talking about the same type of change and arguably should not be using the same set of labels.

To address the issue of how different kinds of change are labelled requires a consideration of not only the coevolutionary model itself, but also of how its substantive meaning has been mapped across application domains; to what extent is it acceptable to change the meaning of a conceptual structure as it is transferred between disciplines? At what point (if any) should different labels be used, and more importantly, at what point should it be acknowledged that the model is inaccurate or its usefulness compromised? In creating a diverse array of meanings for a single set of conceptual labels the danger arises of diluting and eventually losing the original insight, or heuristic device. Transferring concepts between fields of application is a tricky business, and should be pursued with caution. 
Table 1 An evolutionary description of regional water use and management. LU = land use.

\begin{tabular}{|c|c|}
\hline Element type & Example \\
\hline $\begin{array}{l}\text { Variables/attributes for consideration } \\
\text { in the system of interest }\end{array}$ & $\begin{array}{l}\text { Regional LU: actual and potential distributions of LU types (e.g. housing, forest) for } \\
\text { the region } \\
\text { Domestic water use: number and geographical location of different types of houses each } \\
\text { with quantities }\left(\mathrm{m}^{3}\right) \text { and qualities (different standards) of water consumed under different } \\
\text { economic, socio-demographic and technological conditions, and supply routes (ways of } \\
\text { getting water) }\end{array}$ \\
\hline $\begin{array}{l}\text { Characterization/representation of } \\
\text { variation in the variables/attributes } \\
\text { of interest }\end{array}$ & $\begin{array}{l}\text { A set of land parcels each represented by an occurring LU type and a set of potential LU } \\
\text { types that could occur depending on variables such as water availability, soil type, access to } \\
\text { transport and planning zones } \\
\text { Number of households (possibly categorized), each with a demand distribution (volumetric } \\
\text { demand for different water qualities per day, week, month or year), and a supply route } \\
\text { (e.g. mains plumbing, small-scale grey-water re-use or borehole supply) }\end{array}$ \\
\hline $\begin{array}{l}\text { Mechanisms for generating or } \\
\text { renewing variation in the } \\
\text { variables/attributes of interest }\end{array}$ & $\begin{array}{l}\text { LU change: a complex set of economic, socio-demographic, technological, planning and } \\
\text { environmental processes which may result in the generation of new LU types, or ways } \\
\text { of permitting pre-existing LU types to occur in parcels where they previously could not, } \\
\text { or in changes to the intensity of LU, or in changes to the boundaries of land parcels } \\
\text { Socio-demographic, technological or economic processes resulting in changes in household } \\
\text { water use and demand (quantities and qualities), or in changes to household supply route. }\end{array}$ \\
\hline $\begin{array}{l}\text { Mechanisms for winnowing extant } \\
\text { variation i.e. selecting 'fit' variations }\end{array}$ & $\begin{array}{l}\text { Changes in land parcel properties such as water availability, employment availability or } \\
\text { transport accessibility may make some LU types non-viable, either forcing or preventing } \\
\text { change in LU type } \\
\text { Economic pricing of water could select against certain water use behaviours for some } \\
\text { household types, or could induce a change to an alternative supply technology. Water } \\
\text { supply infrastructure capacity in an area may constrain household water use spatially } \\
\text { and/or temporally }\end{array}$ \\
\hline $\begin{array}{l}\text { Mechanisms for providing continuity } \\
\text { for the variable/attribute variation } \\
\text { that survives winnowing }\end{array}$ & $\begin{array}{l}\text { LU types are actively maintained (e.g. urban, agriculture) to meet human requirements } \\
\text { within physical environmental constraints. If there are no humans LU would revert to } \\
\text { natural vegetation. In addition there are human and environmental constraints on } \\
\text { whether LU can change at all, and if it can, how quickly } \\
\text { Households need water for a range of basic uses for human survival. Social resistance to water } \\
\text { pricing for basic services could leading to continued water use behaviour. In addition, } \\
\text { households may change supply option if the current option ceases to be economically viable }\end{array}$ \\
\hline
\end{tabular}

In broad agreement with Winder et al. (2005), we propose that co-evolution, as a type of change, is manifest through populations of discrete, observable entities, individuals or things; it is distinct from (simple or complex) dynamic or (merely) evolutionary change. Abstract theorising has allowed the development of concepts and definition of units of analysis, but it is now time to populate this view of co-evolution with some practical examples as a means of determining its applicability and utility (about which we make no a priori judgements) as a basis for management. The phenomena to be studied must be bounded in operational terms so that we can explore and understand relationships between elements and between separate systems in terms of attributes, processes and mechanisms. The following section documents a process designed to progress the application of the coevolutionary model outside biology and ecology through facilitating structured and principled exploration.

\section{A CO-EVOLUTIONARY PERSPECTIVE ON WATER MANAGEMENT}

A significant problem in applying co-evolutionary interpretations to an issue as complex as water management (or other areas of natural resource management) is the sheer magnitude of coupled processes which require consideration. The classes of phenomena generally denoted as being of relevance to socio-natural co-evolution conform to the classification typically adopted by 'integrative' research agendas; these are sets of structures and processes which exhibit economic, social, technological, environmental and political features. Although this classification scheme appears instinctively useful (conflicts between sets conforming to popular representations of the tensions which characterize contemporary natural resource management challenges), there is no reason (in the metaphysical sense) why coevolutionary models should in principle fall in line with other ways of classifying and structuring the problem. Indeed the difficulties in knowing 'where to look' for co-evolution are manifest in the evolutionary and co-evolutionary descriptions of regional water use and management (Tables 1 and 2, discussed below). Bounding the phenomena of interest in different ways yields different system perspectives which may vary in the degree to which they can be said to exhibit the potential for evolutionary or co-evolutionary change.

In addition, there is a balance to be struck in the search for socio-natural co-evolution between looking for and analysing 
Table 2 A co-evolutionary description of regional water use and management. LU = Land use.

\begin{tabular}{|c|c|}
\hline Element type & Example \\
\hline $\begin{array}{l}\text { A potential co-evolutionary sequence } \\
\text { of change }\end{array}$ & $\begin{array}{l}\text { Spatially diffuse urbanization creates a significant centralized water supply investment cost. } \\
\text { Many domestic customers instead opt to invest in lower cost small-scale water supply } \\
\text { technologies (rainwater, boreholes). Consequent price increases induce increasing numbers } \\
\text { to invest in similar technologies. Such customers become locked in to their investments and } \\
\text { unwilling to reconnect to centralized service, making additional centralized investment } \\
\text { financially unattractive. This in turn limits increases in urban density, which, for health } \\
\text { reasons requires centrally managed water and wastewater service provision. The region } \\
\text { becomes locked into a diffuse urban LU pattern with a decentralized technological regime }\end{array}$ \\
\hline \multirow[t]{2}{*}{$\begin{array}{l}\text { Nature of the pair-wise interactions } \\
\text { between systems (mechanism } \\
\text { and scope) }\end{array}$} & $\begin{array}{l}\text { Spatial and temporal water demand depends on the distribution of LU types. LU change } \\
\text { processes may result in a change in the number and composition of housing stock, and in } \\
\text { the types of inhabitants expected to occupy each house. Changes in inhabitants may change } \\
\text { domestic water-use behaviours. These processes have the potential to affect variation in } \\
\text { water demand (how much, when, in what quality, at what location and through what } \\
\text { means) by households. }\end{array}$ \\
\hline & $\begin{array}{l}\text { As domestic water use changes it may impact on the availability of raw or piped water. As } \\
\text { water levels decrease the LU possibilities for affected parcels of land may be reduced, for } \\
\text { example particular types of agriculture may no longer be viable. Given that public supply } \\
\text { of water typically has priority over other uses, changes in domestic water use might } \\
\text { constrain and influence regional LU patterns through selecting against particular LU types } \\
\text { occurring in particular land parcels }\end{array}$ \\
\hline \multirow[t]{2}{*}{$\begin{array}{l}\text { Effect of the pair-wise interactions } \\
\text { on variation within each system }\end{array}$} & $\begin{array}{l}\text { LU change plays a role in setting the bounds of domestic water use through setting the } \\
\text { number, composition and location of housing (if dense housing is planned then gardens } \\
\text { will be small, restricting water demand for those houses) }\end{array}$ \\
\hline & $\begin{array}{l}\text { Domestic water use varying across a region may influence the set of possible LU cover types } \\
\text { for different land parcels if water availability is restricted. If however water is abundant as } \\
\text { a raw and piped resource, then there is likely to be little direct influence from water demand } \\
\text { to LU }\end{array}$ \\
\hline
\end{tabular}

pair-wise interactions like the classical biological flowerpollinator example, and casting the net of analysis too wide in the hope of capturing some evidence of co-evolutionary dynamic. With the former approach, key influences may be ignored which qualitatively change potentially coevolutionary relationships, and with the latter approach coevolutionary effects may appear ubiquitous and hopelessly entangled. Biological co-evolutionary research has tried both approaches over the past decades. An initially pair-wise approach which is subsequently expanded in scope as required is now recommended (Thompson 1994).

It is our position that difficulties in bounding the natural resource management 'system' under examination increases the need for a structured process to guide the application of the co-evolutionary model. Such a process should ensure that (1) evidence for co-evolution does not arise simply as a consequence of selectively viewing a complex, interconnected, multi-scale set of substantive issues, and (2) management action is based upon empirical evidence gathered and analysed in a defensible manner. We will now describe a process which provides structure to applying the co-evolutionary model to natural resource management.

Given that co-evolutionary systems are essentially reciprocally interacting evolutionary systems, the first task is to identify potentially evolving (sub-)systems that interact in a potentially reciprocal manner. Little general guidance can be given regarding the initial identification of interacting (sub-)systems (these should follow from the literature, from policy or management documentation, etc.), but once identified each (sub-)system should be described with reference to the features identified by Nelson (1995):

- the variables or attributes for consideration in the system of interest,

- a way of characterizing variation within the variables or attributes selected,

- one or more mechanisms through which variation can be generated or renewed in the variables or attributes selected,

- one or more mechanisms for winnowing variation in the variables or attributes selected, and

- one or more mechanisms for providing continuity for variation in the variables/attributes selected.

This list of elements constitutes an evolutionary description of the system concerned and for our purposes provides a definition of an evolutionary process. The mechanisms by which variation can be generated or winnowed or continue, constitute a description of at least some of the ways in which the system may evolve. If the list of elements cannot be articulated in its entirety, it is difficult to see how any claim regarding the operation of co-evolution can be made. There is considerable scope however for articulating each element in different ways as appropriate for the phenomena under study.

To illustrate this part of the process, we provide a description of two aspects of water resource use and 
management at a regional scale using these elements (Table 1). The need to consider land and water in an integrated manner for policy and management purposes is now recognized both in literature (Geerlings \& Stead 2003; Slater et al. 2004; Carter et al. 2005) and legislation such as the EU Water Framework Directive.

The distribution of different land uses across a region and the way in which they change over time will influence water resource availability within that region, with potentially different demand profiles (quantities and qualities of water used over time) associated with each use. Given a finite regional water resource constraint with a particular spatial and temporal distribution, there are limits to the amount of raw water available for abstraction and use, and therefore limits to the possible distribution and intensity of land uses within a region. These limits may be extended through the use of water supply technologies like grey-water recycling that extract more use per unit of raw water, through coordinated supply and sewage treatment systems which abstract water downstream from major sewage discharge locations, or through forms of demand management instrument like pricing, metering or education which reduce water consumption. Alternatively these limits may be reached more quickly if demand rises through the spread of land uses with high water demand like housing with swimming pools or irrigation-demanding agriculture, through unregulated abstraction (no control over location, timing or volume) or a lack of coordination in abstraction so that river abstraction points are not necessarily sited downstream of sewage discharge locations.

Might land-use change influence variation in water use, and reciprocally, might changes in water use influence variation in land use? Are there any co-evolutionary interactions that should be reflected in integrated land and water policy or management action? For example, how should expansion in housing (urban land use) into rural areas be planned in terms of location, timing and density to ensure a sustainable water supply?

Table 1 is in effect two evolutionary descriptions presented together, namely one for land use and one for domestic water use, both at a regional scale. It is not the only possible perspective on, or description of, the interactions between land and water, but one which is of interest with respect to understanding the relationships between land-use change and water use. All elements of the evolutionary description for each (sub-) system could be completed indicating that it is possible to frame each one in evolutionary terms. Now the question is, does each (sub-)system at least partially drive evolutionary change in the other?

The co-evolutionary dynamic can be focused on by undertaking the following tasks:

- characterizing a potential sequence of interactions between the systems that results in reciprocal evolutionary change,

- using the potential sequence as a starting point, identifying the nature of the interaction between the two systems as to interaction mechanism or process and scope of interaction (i.e. for each system does the interaction operate identically across the range of extant variation or are there geographic, social, temporal or some other differences that may affect the outcome?), and

- for both systems (from land-use change to domestic water use and reciprocally, from water use to land-use change), identifying how the process of interaction either generates variation or selects for or against particular variations or configurations and in doing so directs system evolution.

The method described above reflects Thompson's (1994) suggestion to analyse pair-wise interactions as a means of approaching more entangled multiple system co-evolution if the issues are overwhelming.

Continuing the example (Table 1), we provide a co-evolutionary description of regional water use and management (Table 2). Although both land-use change and domestic water use show the potential for evolutionary change (as defined by Nelson), and both interact and influence each other, the nature of this interaction is unclear and mediated. Water use has the potential to act as a winnowing process for land-use through reducing availability (either in the natural environment or within supply infrastructures). However this is only likely to occur under conditions of high demand and/or low resource availability.

Land-use change has the potential to influence variation in the range of possible supply options considered domestically. The processes underlying land-use change will determine the number, type and location of housing within a region and in doing so set bounds on the possible variation of domestic water use both in terms of demand levels and supply options. There is a possibility that diffuse housing expansion may financially influence domestic customers to opt for alternative non-networked supply options depending on price (Table 2).

However the mechanisms which generate, winnow and provide continuity for variation in either land use or domestic water use are more directly related to the economics of water supply and consumption, demographic change, regional economic change and governance and regulation arrangements. This reflects the problem of bounding explored at the start of this section, which is inherent to socio-natural investigation; where do you (not) look to find evidence of co-evolution?

Despite it being likely that there will be an associative relationship between inhabitants, types of houses and types of water-use behaviour, water demand is a direct function of the behaviour of the inhabitants of houses, not of the houses (or the land-use types) themselves. As inhabitants change through demographic, socio-economic and technological processes, so will variation in domestic water use regionally. Given this, where is the co-evolution? One is left with the impression that there might be co-evolution at work, but it is difficult to pin-point in process or effect.

To summarize, our suggested procedure for the identification of socio-natural co-evolutionary processes is as 
follows: (1) identify the evolutionary (sub-)systems/entities, (2) provide a characterization of variation in each system, (3) identify the mechanisms that generate, winnow and provide continuity for variation in each system, (4) describe one or more potential sequences of reciprocal change that result in an evolutionary change in one or more systems, (5) identify possible reciprocal interaction(s) between each system in terms of interaction mechanism/process and scope of interaction, and (6) identify the effect of the reciprocal interaction(s) on each system in terms of generating variation, selecting for or against particular variations (directional selection).

This six-point procedure can in our opinion act as a device for structuring thinking about the presence and nature of co-evolutionary change. If it is not possible to describe the target domain in this way, then either the investigator does not possess a sufficiently clear picture of the domain in terms of the elements, relationships and processes within it, or there are genuine difficulties in framing the domain in coevolutionary terms. Whilst the procedure described does not constitute a critical test for the existence of 'co-evolutionarylike' processes (as framed above), an inability to describe a target domain using the procedure may indicate that changes in the domain cannot be adequately or usefully described in co-evolutionary terms. In either case, further investigation will be required.

A formal comparison between a co-evolutionary interpretation of socio-natural interactions and other water management models is beyond the scope of this investigation. However, it should be noted that there are substantive ontological differences between many contemporary approaches to managing water resources. For example, whilst integrated water resources management (Jonker 2002) advocates the benefits of joined-up planning and intervention between sectors and amongst governance bodies, adaptive management (Walters 1986) endorses a particular style of management founded on experiment and learning. Contrastingly, the coevolutionary model is an epistemological tool, a way of understanding change (that may or may not generate insights which can be exploited for management) rather than a way of managing change. Direct comparisons are thereby of limited value. The reader might usefully refer to recent work by De Groot and Lenders (2006) for a recent survey of approaches to water management.

The value of identifying and understanding the characteristics of co-evolutionary relationships for water policy development will be a function of the status of the insights gained and the availability of appropriate policy mechanisms. In particular, the extent to which new knowledge can be exploited will be determined by the confidence in taking lessons from one point in space and time and using them at other points. This case specificity of actionable knowledge plagues other contemporary approaches to water management and raises issues of policy legitimacy as well as science-society relationships. A co-evolutionary perspective also embraces the possibility that appropriate responses to water problems may be found outside of the water sector; thereby creating niches for new policy tools and confirming the relevance of integrated water resource management as a policy framework.

\section{CONCLUSIONS}

The search for suitable models with which to understand and manage socio-natural interactions presents a significant challenge to both research and practitioner communities, involving the synthesis of appropriate knowledge from a broad range of natural and social sciences. As part of this activity, theories of evolution and co-evolution have been transferred from the biological and ecological sciences to address a range of issues from the global relationship between society and the environment to more specific issues concerning institutional development, economic policy and response to climate change.

Much of this transfer and application has been conducted in a manner that tends only to reinforce the already well-accepted view that socio-natural processes are complex, interwoven, dynamic and inherently uncertain in trajectory. Precious little in terms of practical advice on how to formulate policy has been produced by researchers engaged in transferring such theories. Further, several fractures can be detected in the analogy being made between socio-natural co-evolution and biological coevolution. A change in focus and direction is required to maintain those insights from co-evolutionary theory which are of genuine assistance in making the understanding of socio-natural processes more acute, accurate and more directly relevant to sustainable natural resource management.

Perhaps the analysis presented in this paper could be charged with taking the co-evolutionary analogy too literally, of missing the spirit of the original insight by pedantically scrutinizing its meaning. However, in drawing attention to the implications of imprecise or hasty transfer of models between phenomena, we seek to review the utility or relevance of the insight, and to move beyond the enthusiasm of revelation and take a more critical view of the claims made. It is also true that, in its homeland of biology, the field of co-evolutionary dynamics is itself not static. For example, recent advances have emphasized the role of metapopulations in geographicallystructured co-evolution (Thompson 1999; Thompson et al. 2002). Whilst these developments are potentially useful in the context of natural resources management, we argue that unless a 'simple' version of the model is demonstrably applicable, embellishments of it are unlikely to hold much water.

We advocate that the research community move beyond a consideration of the complex implications of co-evolutionary processes to the establishment of a firm, process-based definition of co-evolution as a type of change. We further argue that research is required to establish whether a common conceptual definition of co-evolution can be used to structure research and inform management across the multiple substantive domains (such as hydrology, technology, sociology and economics) that are the components of this particular socio-natural system. It is too early to say whether such a definition can be formulated, agreed upon and used, 
but it is apparent that the current situation of conceptual diversity may hinder communication and development over the coming years. Having many meanings for the same labels can be counter-productive. The procedure presented above for describing evolutionary and co-evolutionary systems will establish whether the co-evolutionary model has relevance and utility to water resources management.

However, before concluding, it is appropriate to turn to the question of whether a complexity-embracing, co-evolutionary approach contribute to questions of policy? The utility of taking a co-evolutionary perspective on water management issues is yet to be clearly demonstrated. In tandem with this challenge, both researchers and practitioners need to think more generally about the contribution that this kind of explanation can make. After all, evolutionary theories are recognized as being good for explaining past events but poor for predicting and planning future events (Costanza 2003). This question draws attention to a major criticism of a coevolutionary perspective on any policy issue; that it is of little practical use for prescription or intervention.

Our response to this query is informed by Nelson (1995), who, commenting on the evolutionary theory of the law, stated that: 'One might argue that [the limited predictive power and the ad hoc partiality of the theory] would seem to be a big strike against it. On the other hand one can argue that the illumination of the complex contingent processes by which the law evolves is a strength of the theory. Such an analysis reveals the apparent strong predictive power of a simpler theory to be fool's gold'. We partially concur with this conclusion regardless of the (so far) undemonstrated practical utility of co-evolutionary theory (see, however, Sotarauta \& Srinivas 2006, for a recent example of how the label 'co-evolutionary' has been more sensitively and in our view more appropriately used). Exploring sustainable water management from a coevolutionary perspective has, if nothing else, focused attention on the tension between the need to capture a tractable understanding of the world as a basis for management versus a complex, unpredictable and uncertain reality. We argue that limited predictive power and ad hoc partiality, combined with the second-hand nature of the overarching theoretical structure, should provoke a cautious approach to use.

And lest the significance of a commitment to the co-evolutionary model be underestimated, it should be remembered that the specifics of policy and intervention are premised on a particular understanding of how the world works. If the system is believed to behave like a clock, approaches to exploiting system functionality must be commensurate with a belief in the system behaving like a clock, which necessarily limits the type of utility which can be extracted from the system. Unfortunately, the question of how credible a particular interpretation of how the world works needs to be before we base our actions on it, is rarely addressed, thereby providing much opportunity for theory generation and little time for theory evaluation before the next big idea comes round. Whether or not the co-evolutionary model provides a robust interpretation and/or yields tangible practical benefits remains to be seen. But in prompting a dialogue on how we exploit understandings to benefit progress it illuminates the dynamic between knowledge generation and knowledge use which characterizes much of the contemporary relationship between science and society.

\section{ACKNOWLEDGEMENTS}

The development of this paper has benefited from the comments of reviewers and discussions with a number of colleagues, prominent amongst which have been Nick Winder, Roger Seaton, Tim Oxley and Jamie McGlade. Responsibility for final content is ours. We gratefully acknowledge financial support from the European Commission through funding for the 'Aquadapt' project (EVK1-CT-2001-00104).

\section{References}

Aguilera-Klink, F., Perez-Moriana, E. \& Sanchez-Garcia, J. (2000) The social construction of scarcity. The case of water in Tenerife (Canary Islands). Ecological Economics 34: 233-245.

Allen, P.M. (1994) Coherence, chaos and evolution in the social context. Futures 26: 583-597.

Briscoe, T. (1998) Language as a complex adaptive system: coevolution of language and of the language acquisition device. In: Proceedings of 8th Computational Linguistics in the Netherlands, ed. P. Coppen, H. van Halteren \& L. Teunissen, pp. 3-40. Amsterdam, the Netherlands: Rodopi.

Carter, N., Kreutswizer, R.D. \& de Löe, R.B. (2005) Closing the circle: linking land use planning and water management at the local level. Land Use Policy 22: 115-127.

Clark, N., Perez-Trejo, F. \& Allen, P.M. (1995) Evolutionary Dynamics and Sustainable Development: A Systems Approach. Cheltenham, UK: Edward Elgar.

Coleridge, S.T. (1831) Aids to reflection: moral and religious aphorisms. In: The Collected Works of Samuel Taylor Coleridge. Volume 9 (1993), ed. J. Beer., p. 47. Princeton, USA: Princeton University Press.

Costanza, R. (2003) A vision of the future of science: reintegrating the study of humans and the rest of nature. Futures 35: 651-671.

Costanza, R., Stern, D., Fisher, B., He, L. \& Ma, C. (2004) Influential publications in ecological economics: a citation analysis. Ecological Economics 50: 261-292.

Coyne, J.A. \& Orr, H.A. (2004) Speciation. Sunderland, USA: Sinauer Associates.

De Groot, W.T. \& Lenders, H.J.R. (2006) Emergent principles for river management. Hydrobiologia 565: 309-316.

Dijksterhuis, M., Van Den Bosch, F. \& Volberda, H. (1999) Where do new organizational forms come from? Management logics as a source of coevolution. Organization Science 10: 569-582.

Ehrlich, P.R. \& Raven, P.H. (1964) Butterflies and plants: a study in coevolution. Evolution 18: 586-608.

Fiorillo, F. (2001) Rate of growth and sector specialisation coevolution in a Kaldorian export-led growth model. Structural Change and Economic Dynamics 12: 91-114.

Fox C.W., Roff D.A. \& Fairbairn D.J., eds (2001) Evolutionary Ecology: Concepts and Case-Studies. Oxford, UK: Oxford University Press. 
Funtowicz, S. \& O’Connor, M. (1998) The passage from entropy to thermodynamic indeterminacy: a social and science epistemology for sustainability. In: Bioeconomics and Sustainability: Essays in Honor of Nicholas Georgescu-Rogen, ed. K. Mayumi \& J.M. Gowdy, pp.257-286 Cheltenham, UK: Edward Elgar.

Funtowicz, S.O. \& Ravetz, J.R. (1994) The worth of a songbird: ecological economics as a post-normal science. Ecological Economics 10: 197-207.

Funtowicz, S.O., Ravetz, J.R. \& O'Connor, M. (1998) Challenges in the utilisation of science for sustainable development. International Fournal of Sustainable Development 1: 99-108.

Futuyma, D.J. (1986) Evolutionary Biology. Second edition. Massachusetts, USA: Sinauer Associates.

Geerlings, H. \& Stead, D. (2003) The integration of land-use planning, transport and environment in European policy and research. Transport Policy 10: 187-196.

Geldof, G.D. (1995a) Adaptive water management: integrated water management on the edge of chaos. Water Science and Technology 32: 7-13.

Geldof, G.D. (1995b) Policy analysis and complexity - a nonequilibrium approach for integrated water management. Water Science and Technology 31: 301-309.

Giampietro, M. (1994) Using hierarchy theory to explore the concept of sustainable development. Futures 26: 616-625.

Gould, S.J. (2002) The Structure of Evolutionary Theory. Cambridge, USA: Harvard University Press.

Gowdy, J. (1994) Coevolutionary Economics: The Economy, Society and the Environment. Dordrecht, the Netherlands: Kluwer Academic.

Hodgson, G. (1993) Why the problem of reductionism in biology has implications for economics. World Futures 37: 69-90.

Huxley, J.S. (1942) Evolution: The Modern Synthesis. New York, USA: Harper \& Row.

Jonker, L. (2002) Integrated water resources management: theory, practice, cases. Physics and Chemistry of the Earth 27: 719-720.

Kallis, G. (2007) Socio-environmental coevolution: some ideas for an analytical approach. International fournal of Sustainable Development and World Ecology 14: (in press).

Kaufmann, S. (1993) The Origins of Order: Self-Organization and Selection in Evolution. Oxford, UK: Oxford University Press.

Klüver, J. (2002) An Essay Concerning Sociocultural Evolution, Theoretical Principles and Mathematical Models. Dordrecht, the Netherlands: Kluwer Academic Publishers.

Kuznar, L.A. (2001) Ecological mutualism in Navajo corrals: implications for Navajo environmental perceptions and human/plant coevolution. Fournal of Anthropological Research 57: $17-39$.

McIntosh, B.S. \& Jeffrey, P. (2004) Transferring theories of biological (co)evolution to socio-natural science: a reply to Rammel and Staudinger. The International Fournal of Sustainable Development and World Ecology 11: 1-8.

McWhorter, J. (2003) The Power of Babel. London, UK: Arrow.

Mitman, G. (1988) From the population to society: the co-operative metaphors of W.C. Allee and A.E. Emerson. Fournal of the History of Biology 21: 173-194.

Nelson, R.R. (1995) Recent evolutionary theorizing about economic change. Fournal of Economic Literature 33: 48-90.

Nelson R.R. \& Winter S.G., eds (1982) An Evolutionary Theory of Economic Change. Cambridge, USA: Belknap Press of Harvard University Press.
Norgaard, R.B. (1981) Sociosystem and ecosystem coevolution in the Amazon. Journal of Environmental Economics and Management 8: 238-254.

Norgaard, R.B. (1984) Coevolutionary agricultural development. Economic Development and Cultural Change 32: 525-546.

Norgaard, R.B. (1994) Development Betrayed: The End of Progress and a Coevolutionary Revisioning of the Future. New York, USA: Routledge.

Norgaard, R.B. (1995) Beyond materialism: a coevolutionary reinterpretation of the environmental crisis. Reviem of Social Economy 53: 475-492.

Odum, E. (1993) Ecology and Our Endangered Life-support Systems. Sunderland, USA: Sinauer Associates.

Rammel, C. \& Van Den Bergh, J.C.M. (2003) Evolutionary policies for sustainable development: adaptive flexibility and risk minimising. Ecological Economics 47: 121-133.

Rammel, C. \& Staudinger, M. (2002) Evolution, variability and sustainable development. International fournal of Sustainable Development and World Ecology 9: 301-315.

Rammel, C. \& Staudinger, M. (2004) The bridge between diversity and adaptivity: answering McIntosh and Jeffrey. International Fournal of Sustainable Development and World Ecology 11: 924.

Reich, R. (2001) The Future of Success. London, UK: Heinemann.

Rensch, B. (1959) Evolution Above the Species Level. London, UK: Methuen.

Richerson, P.J., Boyd, R. \& Paciotti, B. (2002) An evolutionary theory of commons management. In: The Drama of the Commons, ed. E. Ostrom, T. Dietz, N. Dolsak, P.C. Stern, S. Stonich \& E.U. Weber, pp. 403-442. Washington, USA: National Academy Press.

Robinson, J.B., Francis, G., Legge, R. \& Lerner, S. (1990) Defining a sustainable society: values, principles and definitions. Alternatives 17: 36-46.

Simpson, G.G. (1965) The Geography of Evolution: Collected Essays. New York, USA: Capricorn Books.

Slater, S., Marvin, S. \& Newson, M. (2004) Land use planning and the water sector. Tomn and Country Planning Reviem 65: 375-397.

Sotarauta, M. \& Srinivas, S. (2006) Co-evolutionary policy processes: understanding innovative economies and future resilience. Futures 38(3): 312-336.

Stokes, K.M. (1994) Man and the Biosphere: Tomard a Coevolutionary Political Economy. New York, USA: M E Sharpe.

Tainter, J.A. (1988) The Collapse of Complex Societies. Cambridge, UK: Cambridge University Press.

Thiele, L.P. (1999) Environmentalism for a New Millenium: The Challenge of Coevolution. New York, USA: Oxford University Press.

Thompson, J.N. (1994) The Coevolutionary Process. Chicago, USA: University of Chicago Press.

Thompson, J.N. (1999) The evolution of species interactions. Science 284(5423): 2116-2118.

Thompson, J.N. (2001) The geographic dynamics of coevolution. In: Evolutionary Ecology: Concepts and Case-Studies, ed. C.W. Fox, D.A. Roff \& D.J. Fairbairn, pp. 331-343. Oxford, UK: Oxford University Press.

Thompson, J.N., Nuismer, S.L. \& Gomulkiewicz, R. (2002) Coevolution and maladaptation. Integrative and Comparative Biology 42(2): 381-387.

Tisdell, C. (1998) Biodiversity, Conservation and Sustainable Development. Williston, USA: Edward Elgar. 
Van Den Bergh, J.C.J.M. \& Stagl, S. (2003) Co-evolution of economic behaviour and institutions: towards a theory of institutional change. Fournal of Evolutionary Economics 13: 289317.

Van Den Bergh, J.C.J.M. \& Gowdy, J. (2000) Evolutionary theories in environmental and resource economics: approaches and applications. Environmental and Resource Economics 17: 37-52.
Von Bertalanffy, L. (1968) General System Theory. London, UK: Allen and Lane.

Walters, C. (1986). Adaptive Management of Renemable Resources. New York, USA: McGraw Hill.

Winder, N., McIntosh, B.S. \& Jeffrey, P. (2005) The origin, diagnostic attributes and practical application of co-evolutionary theory. Ecological Economics 54: 347-361. 
